\title{
A quality indicator set for rehabilitation services for people with rheumatic and musculoskeletal diseases demonstrates adequate responsiveness in a pre-post evaluation
}

Anne-Lene Sand-Svartrud ${ }^{1 *}$, Gunnhild Berdal', Maryam Azimi², Ingvild B $\varnothing^{3}$, Turid Nygaard Dager ${ }^{1}$, Siv Grødal Eppeland ${ }^{4}$, Guro Ohldieck Fredheim ${ }^{5}$, Anne Sirnes Hagland ${ }^{6}$, Åse Klokkeide ${ }^{7}$, Anita Dyb Linge ${ }^{8}$, Kjetil Tenneb $\varnothing^{9}$, Helene Lindtvedt Valaas ${ }^{5}$, Ann Margret Aasvold ${ }^{10}$, Hanne Dagfinrud ${ }^{1}$ and Ingvild Kjeken ${ }^{1}$

\begin{abstract}
Background: Quality of care is gaining increasing attention in research, clinical practice, and health care planning. Methods for quality assessment and monitoring, such as quality indicators (QIs), are needed to ensure health services in line with norms and recommendations. The aim of this study was to assess the responsiveness of a newly developed QI set for rehabiliation for people with rheumatic and musculoskeletal diseases (RMDs).

Methods: We used two yes/no questionnaires to measure quality from both the provider and patient perspectives, scored in a range of 0-100\% (best score, 100\%). We collected QI data from a multicenter stepped-wedge clusterrandomized controlled trial (the BRIDGE trial) that compared traditional rehabilitation with a new BRIDGE program designed to improve quality and continuity in rehabilitation. Assessment of the responsiveness was performed as a pre-post evaluation: Providers at rehabilitation centers in Norway completed the center-reported Qls ( $n=19$ structure indicators) before (T1) and 6-8 weeks after (T2) adding the BRIDGE intervention. The patient-reported Qls comprised 14 process and outcomes indicators, measuring quality in health services from the patient perspective. Pre-intervention patient-reported data were collected from patients participating in the traditional program (T1), and post-intervention data were collected from patients participating in the BRIDGE program (T2). The patient groups were comparable. We used a construct approach, with a priori hypotheses regarding the expected direction and magnitude of PR changes between T1 and T2. For acceptable responsivess, at least 75\% of the hypotheses needed to be confirmed.

\footnotetext{
* Correspondence: anne-lene.svartrud@diakonsyk.no

'National Advisory Unit on Rehabilitation in Rheumatology, Diakonhjemmet Hospital, PO Box 23, Vinderen, N-0319 Oslo, Norway

Full list of author information is available at the end of the article
}

(c) The Author(s). 2021 Open Access This article is licensed under a Creative Commons Attribution 4.0 International License, which permits use, sharing, adaptation, distribution and reproduction in any medium or format, as long as you give appropriate credit to the original author(s) and the source, provide a link to the Creative Commons licence, and indicate if changes were made. The images or other third party material in this article are included in the article's Creative Commons licence, unless indicated otherwise in a credit line to the material. If material is not included in the article's Creative Commons licence and your intended use is not permitted by statutory regulation or exceeds the permitted use, you will need to obtain permission directly from the copyright holder. To view a copy of this licence, visit http://creativecommons.org/licenses/by/4.0/ The Creative Commons Public Domain Dedication waiver (http://creativecommons.org/publicdomain/zero/1.0/) applies to the data made available in this article, unless otherwise stated in a credit line to the data. 
(Continued from previous page)

Results: All eight participating centers and 82\% of the patients (293/357) completed the QI questionnaires. Responsiveness was acceptable, with 44 of 53 hypotheses (83\%) confirmed for single indicators and 3 of 4 hypotheses (75\%) confirmed for the sum scores.

Conclusion: We found this QI set for rehabilitation to be responsive when applied in rehabilitation services for adults with various RMD conditions. We recommend this QI set as a timely method for establishing quality-ofrehabilitation benchmarks, promoting important progress toward high-quality rehabilitation, and tracking trends over time.

Trial registration: The study is part of the larger BRIDGE trial, registered at ClinicalTrials.gov (Identifier: NCT03102814).

Keywords: Rehabilitation, Musculoskeletal disease, Quality indicator, Health care, Responsiveness

\section{Background}

In recent decades, new knowledge has led to earlier diagnosis and more effective pharmacological and surgical treatment for people with rheumatic and musculoskeletal diseases (RMDs) [1]. Nevertheless, many in this population experience a suboptimal effect of such treatments and need rehabilitation services in primary and secondary health care $[2,3]$. Unmet needs are often related to persistent or fluctuating symptoms such as pain, fatigue, stiffness, and joint swelling [4] and can be reflected in individual rehabilitation goals. These goals may span several areas, including physical or mental functioning, personal activities of daily living, social participation, education, and work productivity [5-7].

The wide range of rehabilitation needs calls for individualized interventions, a multidisciplinary approach, and coordination across levels of care to ensure continuity in rehabilitation pathways. Furthermore, sufficient time is needed for individuals to establish new habits and lifestyle changes beyond the institutional setting [8-10]. The same requirements also characterize good quality in rehabilitation [11]. However, important gaps persist between these recommendations and current delivery of rehabilitation services [12]. In Norway, measures to improve the quality of rehabilitation have been recommended particularly to address the documented lack of coordination and communication across care levels and the lack of patient involvement in planning of follow-up interventions after rehabilitation $[13,14]$.

Although "quality" is a rather abstract term, the use of quality indicators (QIs) may enable practical evaluation and improvement of quality [15]. A QI can be defined as "a measurable element of practice performance for which there is evidence or consensus that it can be used to assess the quality, and hence change in the quality, of care provided" ([16], p. 104). QIs often are related to Donabedian's model of quality in health care and the interplaying triad of structure, process, and outcomes of care $[15,17-20]$.
An expert group of researchers, patient research partners, and clinicians in Norway has recently developed a set of QIs for monitoring, evaluating, and improving the quality of rehabilitation in RMDs [21]. The QI set consists of two separate questionnaires: one for rehabilitation providers (addressing structure QIs) and one for patients (addressing process and outcome QIs) [21]. Developers and users of the instrument used the Rand/ UCLA Appropriateness Method to agree on content validity [21]. In the pilot testing, the QI set was appraised as feasible for monitoring quality in rehabilitation in primary and secondary care, and face validity was regarded as good [21], but further investigation of measurement properties was suggested. Especially, the QI set's ability to detect change over time (responsiveness) was of interest for its use in measuring quality improvement in rehabilitation services. Thus, the aim of our study was to assess the responsiveness of a quality indicator set for rehabilitation for people with RMDs [21].

\section{Methods}

\section{Study design and clinical settings}

We tested the QI set in the multicenter stepped-wedge, cluster-randomized controlled BRIDGE trial [22], which aimed to improve continuity and quality in rehabilitation for people with RMDs. The National Advisory Unit on Rehabilitation in Rheumatology recruited participating rehabilitation centers $(n=8)$ in different regions of Norway. The centers started the trial simultaneously and acted as controls (delivering traditional rehabilitation programs) until an allocated point in time for each center to switch to the intervention phase (adding the new BRIDGE program to the traditional programs). Assessment of the responsiveness of the QI set was performed as a pre-post evaluation, before and after the addition of the new BRIDGE program.

Health professionals at the centers recruited patients at admission to rehabilitation. Patient-reported data were collected at admission and discharge from rehabilitation in secondary care and in the subsequent follow- 
up period at home (2, 7, and 12 months after admission). Eligible patients were aged $\geq 18$ years and admitted to rehabilitation with one of the following diagnoses: inflammatory rheumatic diseases, systemic connective tissue diseases, osteoarthritis, osteoporosis, fibromyalgia or widespread pain, or non-specific low back, neck, or shoulder pain (persistent for more than 3 months). Because the electronic data collection and questionnaires were available only in Norwegian, patients needed to be proficient in Norwegian and to have a personal electronic credential for secure identification online. Further, they needed internet connection, and a personal computer, tablet computer, or smartphone. Patients with fracture(s), cognitive impairment, or severe psychiatric disorder(s) were excluded. Eligible patients received verbal and written information about the study. Those who decided to participate provided written informed consent. The study was approved by the Norwegian Regional Committee for Medical Research Ethics (REK South-East, 2017/665).

\section{The BRIDGE program}

The main elements of the BRIDGE program are described in Table 1. At each center, the providers used a fidelity check list to monitor whether they delivered the program according to the BRIDGE protocol.

\section{Data collection and measurements}

At two time points, the head of each center completed the center-reported QI questionnaire in telephone-based interviews conducted by the central project coordinator (ALSS). The first interview was performed at the beginning of the study while the centers were still delivering traditional programs (T1). Using an interview guide based on the Scandinavian Team Arthritis RegisterEuropean Team Initiative for Care Research (STARETIC) rehabilitation framework [25], the head of each center also gave detailed information about the content and organization of the rehabilitation program delivered at T1. The second interview took place $6-8$ weeks after the addition of the BRIDGE program (T2).

Two months after the rehabilitation stay, all patients completed the patient-reported QI questionnaire. We collected patient-reported T1 data from patients participating in traditional rehabilitation programs (the T1group) and T2 data from patients participating in the BRIDGE program (the T2-group). In this manner, we measured quality of rehabilitation services (at the institutional level) at $\mathrm{T} 1$ and $\mathrm{T} 2$ from the perspective of the users.

\section{A Q I set for the rehabilitation of people with RMDs}

Providers completed a questionnaire addressing 19 structure indicators of quality. These indicators measured organizational aspects in which the rehabilitation occurs, e.g., whether written procedures, method descriptions, and/or checklists are currently available and part of the daily routine.

Patients responded to another questionnaire, comprising 14 indicators regarding process and outcome indicators of quality. Process indicators $(n=11)$ measure factors related to giving and receiving care, in the form of actions and interactions between providers and patients in the actual clinical setting [20,21]. Outcome indicators $(n=3)$ measure the effects of rehabilitation on defined outcomes, related to attainment of rehabilitation goals, improvements in function, and/or improvements in health-related quality of life $[20,21]$. Taken together, the main themes covered by the QI set are as follows: 1 ) patient participation in goal setting and the rehabilitation process; 2) follow-up plan and continuity across levels of care; and 3) assessment, outcomes, and timepoints of evaluation. The QI set is presented in Table 2 . The content of many structure indicators matches the

Table 1 Elements of the BRIDGE program, aimed at strengthening the quality of rehabilitation services

\begin{tabular}{ll}
\hline Structured goal-setting & $\begin{array}{l}\text { Patients developed } 1-5 \text { individual rehabilitation goals in collaboration with clinicians. The goals were } \\
\text { recorded in the Patient-Specific Functional Scale [23, 24], and scored according to experienced difficulty at } \\
\text { every reporting time point in the trial. }\end{array}$
\end{tabular}

A written rehabilitation plan

A tailored follow-up, including plans for self-management

Individualized written feedback
A written rehabilitation plan for each patient included the individual goals and corresponding goal-directed interventions.

The patient and the rehabilitation team developed a plan for tailored follow-up in the first period after discharge. One month after discharge, all participants received a telephone call from the rehabilitation center, addressing 1) progress towards goals, 2) adherence to self-management strategies (plans for selfmanagement), and 3) whether necessary contact with caregivers in the patient's home setting was established. The follow-up interventions were tailored according to patient's needs and available resources in their municipality.

Digital self-reporting enabled individualized graphic feedback throughout the whole rehabilitation period. Data reported in a rehabilitation core set of questionnaires were presented as clinical graphs showing current status and development over time. Participants could use the graphs to monitor their own progress and share information with important caregivers across levels of care.

Motivational interviewing
Motivational interviewing was used in the goal-setting talks and the telephone follow-up calls, in accordance with guiding booklets designed for both clinicians and patients. 
Table 2 Main themes and indicators in a quality indicator set for use in rehabilitation [21]

\begin{tabular}{|c|c|c|}
\hline \multirow[t]{2}{*}{ Main themes } & \multicolumn{2}{|r|}{ Structural quality indicators/center-reported: } \\
\hline & $\mathrm{I}$ & Question (yes/no) \\
\hline \multirow{3}{*}{$\begin{array}{l}\text { Patient participation in } \\
\text { goal setting and } \\
\text { rehabilitation process }\end{array}$} & $\mathrm{C} 01$ & C1. P shall participate in setting rehab goals \\
\hline & $\mathrm{CO2}$ & $\begin{array}{l}\text { C2. P shall participate in planning his/her rehab } \\
\text { process. }\end{array}$ \\
\hline & $\mathrm{CO3}$ & $\begin{array}{l}\text { C3. A template is used to prepare an individual rehab } \\
\text { plan for P. }\end{array}$ \\
\hline
\end{tabular}
continuity across levels of care

C04 C4. P shall participate in evaluating his/her ongoing process.

C05 C5a. There are at least two meetings between P and the team ${ }^{\mathrm{a}}$.

C09 C7a. P shall participate in preparing a specified written follow-up plan (aside from the epicrisis) for the followup process after the rehab period. This plan shall also
Assessment, outcomes, and time-point of evaluation include P's own efforts to maintain or improve function/health.

C10 C7b. If there is a need for health care support after the rehab period, the relevant personnel are to be informed about the plan or participate in the development of the follow-up plan.

C06 C5b. P is asked before meetings if he/she wants his/ her next of kin to attend any of the meetings.

C07 C5c. P is asked before meetings if he/she wants some of the external professionals ${ }^{b}$ he/she will relate to after the rehab. to attend any of the meetings.

C08 C6. The rehab unit uses reliable ${ }^{c}$ questionnaires and/or functional tests to assess physical, mental, and/or social conditions.

P's goal/goal attainment is to be assessed ...

C11 C8a ... . with a reliable ${ }^{c}$ instrument.

C12 C8b.... at the beginning and the end of the rehab period.

C13 C8c. ... 3-6 months after the rehab period. $\mathrm{P}^{\prime} \mathrm{s}$ function is to be registered...

C14 C9a ... using a reliable ${ }^{c}$ instrument.

C15 C9b.... at the beginning and the end of the rehab period.

C16 C9c. ... 3-6 months after the rehab period. $\mathrm{P}^{\prime} \mathrm{s}$ health-related quality of life is to be assessed ...

C17 C10a. ... using a reliable ${ }^{c}$ instrument.

C18 C10b.... at the beginning and the end of the rehab period.

C19 C10c. ... 3-6 months after the rehab period.

\section{Process quality indicators/patient-reported:}

I Question (yes/no)

P04 P4. Were you actively involved in setting specific goals for the rehab period?

P03 P3. Was a written plan developed for the rehab period (comprising your rehab goals, what you should practice, etc.)?

P05 P5. Were you actively involved in preparing a specific written plan for the rehab period (mentioned in q. 3)?

P06 P6a. Did you participate in at least two meetings with the team ${ }^{a}$ during which your goal(s) and goal attainment so far were discussed?

P09 P7. Apart from regular epicrisis, was a written plan developed for the period after rehab, including what you were expected to work on yourself? (if you have answered "yes" to q. 7, go to 9. 8. If you have answered "no" to 9. 7, go to q. 9)

P10 P8a. Did you participate in developing the plan (q. 7)?

P11 P8b. As a part of this plan, were you consulted about whether you needed follow-up from external personnel ${ }^{b}$ after the rehab. Period?

P07 P6b. Were you asked if you wanted your next of kin to attend any of the meetings?

P08 P6c. Were you asked if you wanted professionals ${ }^{b}$ you will relate to after the rehab period to attend any of the meetings?

P01 P1. Were your health condition and life situation assessed during the first days of your rehab period? (Answer "no" if both aspects were not assessed) (If you have answered "yes" to question number 1, go to question number 2. If you have answered "no" to question number 1, go to question number 3).

P02 P2. Did the assessments include both a physical examination and questions about mental and social conditions, network, home situation, and - if relevant your work situation?

\section{Outcome quality indicators/patient-reported:}

P12 P9. As a result of the rehab period, have you achieved one or several goals that are important to you?

P13 P10. As a result of the rehab period, have you achieved an improvement in your physical, mental, and/or social functioning that is important to you?

P14 P11. As a result of the rehab period, do you think your quality of life has improved?

I Indicator number, $C_{x}$ Center-reported + question number, $P x$ Patient-reported + question number, $P$ The patient/user, rehab Rehabilitation, $q$ question number, ${ }^{a}$ the team $=$ the interdisciplinary team, or a professional representing the team; ${ }^{b}$ external professionals = external personnel, such as a physiotherapist, general

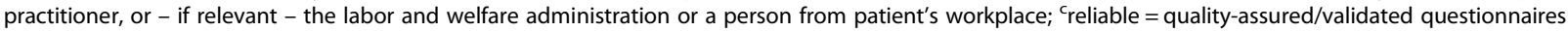
or tests

content of process and/or outcome indicators, which allows for measuring quality in rehabilitation services from the system and user perspectives, respectively.

Because the elements in the BRIDGE program (Table 1) to a large degree mirror the items in the QI set (Table 2), we expected that the QI set would capture improved or maintained quality of rehabilitation between T1 and T2 (Fig. 1). Maintained quality was favorable if the quality at $\mathrm{T} 1$ already was in line with the normative standards reflected in the quality indicators. If not, improved quality was favorable. 


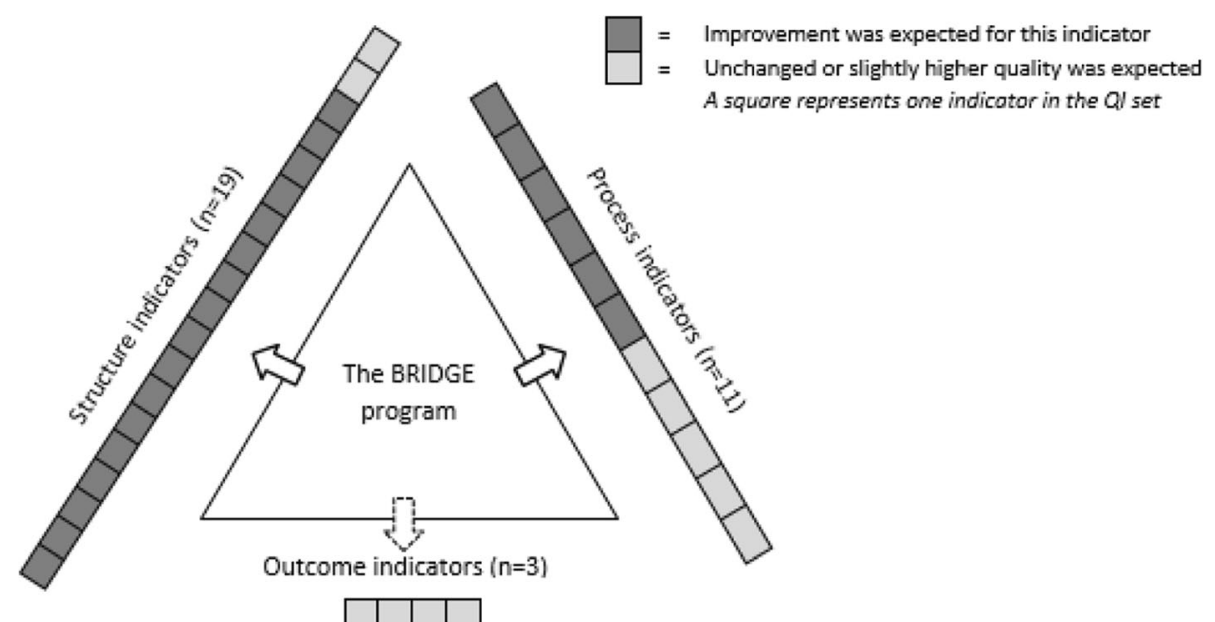

Fig. 1 Expected influence of the BRIDGE program on "A quality indicator set of rehabilitation for RMDs"

Response options and scoring alogrithm Achievements (yes/no) of items in the QI set were measured using pass rates (PRs). Based on responses from the participant (provider or patient), calculations comprised single indicator PRs and total PRs. Single indicator PRs were calculated as the total number of participants who answered "yes" for a particular indicator divided by the total number of participants who answered "yes" or "no" for the same indicator. The scores were normalized to 100 to allow PRs to be reported as percentages.

Single indicator PRs range from 0 to $100 \%(100 \%=$ all eligible participants answered "yes" to this indicator). Total PRs represent the total of "yes" answers from a participant divided by eligible QI items (denominator) for the same participant. Eligible QI items in the centerreported questionnaire are always $n=19$. Eligible QI items in the patient-reported questionnaire are at least $n=11$ out of 14 but can vary. As an example: A patient who answers "yes" to question 1 (P1) goes to the additional question 2 (P2) (as seen in Table 2), resulting in $\mathrm{n}=11+1$ for a denominator of 12 . In the same way, an answer "yes" to question 7 (P7) makes questions 8a (P8a) and 8b (P8b) eligible, resulting in $\mathrm{n}=11+2$, for a denominator of 13. Finally, "yes" answers to both questions 1 and 7 result in $n=11+1+2$, for the maximum denominator of 14 . Total PRs also range from 0 to $100 \%$, with $100 \%$ indicating the best quality in rehabilitation score, implying that the participant answered "yes" to all eligible items in the particular questionnaire.

\section{The STAR-ETIC rehabilitation framework}

The STAR-ETIC framework was developed for describing complex rehabilitation interventions and comparing the content of rehabilitation programs across different sites $[25,26]$. We used the framework to collect information about content and organization of the rehabilitation program delivered at T1. The framework covers clinical setting; type of professions in the rehabilitation team; standards for family involvement and follow-up-management; use of rehabilitation goals, assessments, and evaluations; interventions (content and modalities); and outcomes.

Other measurements We obtained demographic data about the patients at baseline. To assess the impact of data clustering from the multicenter design, we also used baseline data for the primary and secondary outcomes in the BRIDGE trial. The primary outcome was goal attainment, as measured by the Patient-Specific Functional Scale (PSFS) [23, 24]. Secondary outcomes were physical function, measured by the 30-s sit-to-stand test (30 secSTS) [27-29], and health-related quality of life (HRQoL), measured by the EuroQoL 5D- 5L-healthrelated quality of life (EQ. 5D-index and EQ. 5D-vas) [29, 30]). Norwegian versions of all instruments, translated following international guidelines, have been tested for psychometric properties with satisfactory results in RMD populations in rehabilitation settings in primary and secondary care [29].

On the PSFS (open-ended categories), patients report up to five activites that they currently find difficult to perform because of their health condition. Each activity is scored according to experienced performance on an 11 -point scale $(0-10$, with 0 indicating "unable to perform") $[24,29]$. In the EQ. 5D-index, patients report their level of perceived problems in five dimensions of health (mobility, self-care, usual activities, pain/discomfort, and anxiety/depression; 5 levels, with 1 indicating no problems and 5 indicating extreme problems). In the EQ. 5D-vas, patients rate their current health state on a $100-\mathrm{mm}$ visual analog scale (0-100, with 0 indicating 
"The worst health you can imagine" and 100 indicating "The best health you can imagine") [29, 30]. In the performance-based test (30 secSTS), the patient, seated in a chair, rises to a full standing position and then sits down again. According to specific performance instructions, patients complete as many full stands as possible within $30 \mathrm{~s}[28,29]$.

\section{Responsiveness}

Responsiveness has been defined by the COnsensusbased Standards for the selection of health status Measurement INstruments (COSMIN) panel as "the ability of an instrument to detect change over time in the construct to be measured" ([31], p. 742). In this study, we used a construct approach to examine responsiveness [32] because no gold standard is available. Based on current evidence, previous pilot testing [21], and the BRIDGE fidelity checklist, three of the authors (IK, GB, and ALSS) developed a priori hypotheses regarding the expected direction and magnitude of PR changes between T1 and T2. We discussed our hypotheses in a research group with nurses, patient research partners, and a physiotherapist. In accordance with de Vet [33], high responsiveness was indicated if at least $75 \%$ of the predefined hypotheses were confirmed.

The rationales for the hypotheses were based on results from the pilot study, other previous research, expert opinions, and fidelity checklist and guiding booklets available in the BRIDGE trial. The rationales are given in detail in Additional file 3. In short, we developed four hypotheses for median total PRs and 1-3 hypotheses for PR changes for each single indicator. Regarding total PR changes, we included hypotheses for the largest diagnose groups in our trial (inflammatory rheumatic disease, and fibromyalgia/widespread pain, respectively). We expected the change score for total PR to be small to moderate for both subgroups, applied to process and outcome indicators, respectively. Regarding single indicators, we expected improved PRs for QIs that were addressed by the BRIDGE program: patient participation in 1) setting goals, 2) developing a written rehabilitation plan, 3) meeting(s) where goals and/or ongoing rehabilitation process were discussed, 4) consultation(s) about needs for the follow-up period, 5) developing a written follow-up plan, and 6) involvement of externals in planning follow-up. Concerning assessments and time-points of evaluation, we expected improved PRs for 1) use of reliable questionnaires/tests, 2) evaluation of goal attainment, function, and HRQoL at the start and end of the rehabilitation intervention in specialist care, and 3) 3-6 months after discharge (structure). We expected no change for QIs regarding initial bio-psycho-social assessment (process) and no change or little improvement for QIs regarding patient's outcomes. Involving externals (i.e., next of kin or services in primary care) was expected as part of the follow-up plan, but invitations to meetings for next of kin or external services were not included in the BRIDGE program. Hence, we did not expect changes in QIs regarding invitation to meetings for next of kin or external services.

\section{Data analysis}

We used STATA IC v14 for statistical analysis. To compare the baseline characteristics of patients in the $\mathrm{T} 1$ and T2-groups, we used the independent samples t-test, Pearson's Chi square test, and the Mann-Whitney U test. We set the significance level at 0.05 . To assess the impact of clustering in each group, we calculated intraclass correlation coefficients (ICCs) for primary and secondary outcomes.

In testing hypotheses regarding responsiveness, we used descriptive statistics to examine the median PR values and change scores for total PRs and single indicator PRs, respectively.

Based on absolute changes, we used the following criteria for indicating the magnitude of changes: 1) $0 \%$, no change; 2 ) $1.0-12.5 \%$, small change (change for $1 / 8$ participating centers); 3) $12.6-25 \%$, moderate change (change for $2 / 8$ participating centers); and 4) $25.1-100 \%$, considerable change (change for 3 or more participating centers). We used the same criteria for the magnitude of changes in patient-reported quality: $1.00-12.5 \%$, small change; $12.6-25 \%$, moderate change; and $25.1-100 \%$, considerable change.

Returned QI questionnaires were considered incomplete and not included in further analyses if more than $50 \%$ of the QI items had not received a "yes" or "no" response.

\section{Results}

\section{Rehabilitation at participating centers}

All eight centers were organized in secondary care (specialized rehabilitation), with a minimum of four different professions in the multidisciplinary teams. The teams included physicians, physiotherapists, occupational therapists, nurses, and social workers in all centers except center 6 (no nurse) and center 4 (no social worker). Additionally, the teams included a nutritionist or dietitian at six centers, a sport educator at three centers, and a psychologist at one center. Most centers delivered inpatient stays for 3-4 weeks, and two hospital departments delivered a shorter stay (2 weeks), as either inpatient (center 2) or outpatient (center 6) rehabilitation. Length of stay was predetermined, but postponed discharge was allowed in cases of vacancy (centers 1, 3, 4, 8 ). The rehabilitation programs were developed for different patient groups. The primary group was inflammatory arthritis at all the hospital departments and 2/5 
rehabilitation centers, fibromyalgia/widespread pain at centers 4 and 7, and unspecific low back, neck, or shoulder pain at center 5 (see Additional file 1).

At all centers, the content of rehabilitation comprised a combination of group sessions, individual sessions, and self-training. The treatment sessions were comprehensive, including topics like training, physical activity, activities of daily living, pacing, planning and adaptations. Further, counseling regarding coping (pain, fatigue, sleep, or stress), lifestyle changes (physical activity, exercise, weight control, smoking), disease information and medical treatments. Topics like family and other social relationships, work and work adaptations, social services and rights were also included, as well as mindfulness and relaxation.

\section{Patient participants}

The study included 357 participants (200 in the T1group, 157 in the T2-group), and their characteristics are summarized in Additional file 2. The groups were comparable for all baseline variables except age, diagnosis, and disease duration (Additional file 2). The differences in age and disease duration were not considered clinically important, and except for differences in diagnoses, the between-group comparability was considered acceptable. Most patients had inflammatory rheumatic disease ( $72 \%$ in the $\mathrm{T} 1$-group, $54 \%$ in the $\mathrm{T} 2$-group), or fibromyalgia/widespread pain (10, 32\%). For other patients the primary diagnose was unspecific low back-, neck-, or shoulder pain, connective tissue disease, or osteoarthritis. None of the included patients had osteoporosis as the primary diagnose (see Additional file 2).

The patients who did not complete the QI questionnaire did not differ systematically by baseline.

\section{Assessment of responsiveness}

The ICCs for the outcomes of interest were small $\left(\mathrm{ICC}_{\mathrm{psfs}}=0.08, \quad \mathrm{ICC}_{30 \mathrm{sec}}=0.03, \quad \mathrm{ICC}_{\mathrm{EQ} 5 \text { Dindex }}=0.06\right.$, $\left.\mathrm{ICC}_{\mathrm{EQ} 5 \mathrm{Dvas}}=0.02\right)$, indicating a low impact of clustering. Consequently, we pooled patient-reported data from different centers for calculations of total PRs and single indicator PRs.

A total of $161 / 200(80.5 \%)$ patients in the T1-group and 132/157 (84\%) in the T2-group, completed the QI questionnaire. The response rate from participating centers was $100 \%$ (no missing items).

Among 62 predefined hypotheses for change in single indicator PRs, 9 (14.5\%) were not applicable because of the observed distribution of answers at T1. For three structure indicators, there were no "yes" answers at T1, so that hypotheses about "all centers who answered 'yes' at $T 1$ are expected to answer 'yes' at $T 2$ " were not applicable $(n=3)$. For three other structure indicators, there were zero "no" answers at T1, so that the following hypotheses were not applicable: "all centers who answered 'no' at $T 1$ are expected to answer 'yes' at T2" ( $\mathrm{n}=3$ hypotheses), and "the change score for this indicator is expected to be [magnitude of change is described]" $(n=3)$.

Of the remaining 53 hypotheses for single indicators, 44. (83\%) were confirmed. Regarding change scores in median total PRs, three of four hypotheses were confirmed. Taken together, the observed change scores were consistent with $\geq 75 \%$ of the predefined hypotheses, indicating adequate responsiveness for the rehabilitation QI set. These findings are presented in more detail in Table 3 and Additional file 3.

\section{Direction of change}

As hypothesized, the changes in total PRs were in the direction of improvement for all dimensions of quality in rehabilitation (structure, process, and outcomes), with the largest improvements for structure indicators. The center-reported quality at T2 was high and comparable across all participating centers (PR total ranging from 90 to $95 \%$ ), in spite of differences at T1 (PR total ranging from 16 to 68\%) (Fig. 2). All but two hypotheses for single indicators were also confirmed. However, there was a negative direction for two out of three hypotheses concerning outcomes, for which a positive was expected: $\mathrm{H}_{\text {single }} 60$ (achieved important goals) and $\mathrm{H}_{\text {single }} 62$ (improved quality of life; see Table 3).

\section{Magnitude of change}

The expected magnitudes of change were confirmed for each structure indicator, with four exceptions (Table 3): observed improvement was smaller than expected for C12 (patient's goal/goal attainment is to be assessed with a reliable instrument at the beginning and the end of the rehabilitation period), and observed improvements were larger than expected for $\mathrm{C} 03$ (use of a template to prepare a rehabilitation plan for the patient), C04 (patient participation in evaluation of their ongoing process), and C09 (patient participation in preparing a written followup plan), respectively. In contrast to the results for $\mathrm{C} 03$, the observed improvements were smaller than expected for the matching process indicators P03 and P05 (patient participation in developing and use of a written rehabilitation plan). Smaller improvement than expected was also found for the process indicator P06 (participating in at least two meetings with team member(s)).

As hypothesized, PRs were particularly low for indicators concerning access to meetings for next of kin or external personnel at $\mathrm{T} 1$ and $\mathrm{T} 2$, respectively (Fig. 3). At both points in time, PR values below $16 \%$ were observed for both process indicators (P07, P08) and the matching structure indicators $(\mathrm{C06}, \mathrm{C} 07)$ (Fig. 3). 
Table 3 Expected and observed change scores for quality indicators

\section{a. Changes in median total pass rates}

Structural QIs (center-reported, $n=8$ )

Process and outcome QIs (patient-reported, $n=132-161$ )

Process QIs in subgroups (subgroup1 = inflammatory rheumatic disease, $n=74-114$ ) (subgroup2 = fibromyalgia or chronic widespread pain, $n=14-40$ )

Outcome QIs in subgroups (subgroup1 = inflammatory rheumatic disease, $n=74-114$ ) (subgroup2 = fibromyalgia or chronic widespread pain, $n=14-40$ )

\section{IN TOTAL (changes in median total pass rates)}

\section{b. Changes in single items pass rates}

Structural QIs (center-reported, marked C)

Process QIs (patient-reported, marked P)

Patient participation in goal setting and rehabilitation process

C01. P shall participate in setting rehab goals.

P04. Were you actively involved in setting goals for the rehab period?

C02. P shall participate in planning his/her own rehab process.

C03. A template is used to prepare an individual rehab plan for $\mathrm{P}$.
P03. Was a written plan developed for the rehab period (comprising
your rehab goals, what you should practice, etc.)?
P05. Were you actively involved in preparing the written rehab plan?
C04. P shall participate in evaluating his/her ongoing process.

C05. There are at least two meetings between $\mathrm{P}$ and the team ${ }^{\mathrm{a}}$.

P06. Did you participate in at least two meetings with the team ${ }^{\text {a }}$ at which your goal(s) and goal attainment so far were discussed?

Follow-up plan and continuity across levels of care

C09. P shall participate in preparing a specific written follow-up plan (aside from the epicrisis) for the follow-up process after the rehab period. This plan shall also include P's own efforts to maintain or improve function/health.

$\begin{aligned} & \text { Hypo- } \\ & \text { theses }\end{aligned}$
$\begin{aligned} & \text { direction } \\ & \text { change }\end{aligned}$
$H_{\text {total }} 1$ yes
$H_{\text {total }} 2$ yes
$H_{\text {total }} 3$ yes

$\mathrm{H}_{\text {total }} 4$ yes

theses direction ${ }^{1}$ of change

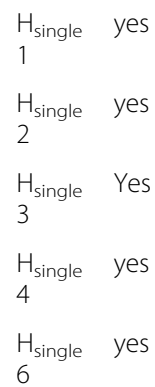

6

$\mathrm{H}_{\text {single }}$ yes 5

$\mathrm{H}_{\text {single }}$ yes

7

$\mathrm{H}_{\text {single }} \mathrm{Yes}$

8

$\mathrm{H}_{\text {single }} \mathrm{Yes}$

$\mathrm{H}_{\text {single }}$ yes

13

$\mathrm{H}_{\text {single }}$ yes

14

$\mathrm{H}_{\text {single }}$ yes

10

$\mathrm{H}_{\text {single }}$ yes

11

$\mathrm{H}_{\text {single }}$ Yes

12

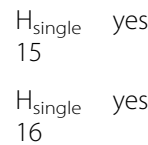

\begin{tabular}{|c|c|}
\hline $\begin{array}{l}\text { Expected } \\
\text { magnitude of } \\
\text { change }\end{array}$ & $\begin{array}{l}\text { Observed } \\
\text { magnitude } \\
\text { change }\end{array}$ \\
\hline $\begin{array}{l}\text { moderate to } \\
\text { high }\end{array}$ & high \\
\hline $\begin{array}{l}\text { small to } \\
\text { moderate }\end{array}$ & small \\
\hline $\begin{array}{l}\text { small to } \\
\text { moderate (both } \\
\text { groups) }\end{array}$ & $\begin{array}{l}\text { small (both } \\
\text { groups) }\end{array}$ \\
\hline zero to small & $\begin{array}{l}\text { zero } \\
\text { (subgroup1) } \\
\text { moderate } \\
\text { (subgroup2) }\end{array}$ \\
\hline
\end{tabular}

Confirmed hypothesis

Expected magnitude of

Observed

Confirmed change

$$
\text { change }
$$

hypothesis

All (100\%)

small to

moderate

moderate

Similar or small small

All (100\%)

All (100\%)

small to

moderate

moderate

All (100\%)

small to

moderate

high

$1 / 2$

moderate

small

0/1

moderate

small

0/1

All (100\%)

All (100\%)

small to

high

moderate

All (100\%)

small to

small

$2 / 2$

moderate

small

0/1

All (100\%)

All (100\%)

small to

moderate high

$1 / 2$ 
Table 3 Expected and observed change scores for quality indicators (Continued)

\begin{tabular}{|c|c|c|c|c|c|}
\hline \multirow{2}{*}{$\begin{array}{l}\text { C10. If there is a need for health care support after the rehab period, } \\
\text { the relevant personnel are to be informed about the plan or } \\
\text { participate in the development of the follow-up plan. }\end{array}$} & $\begin{array}{l}\mathrm{H}_{\text {single }} \\
17\end{array}$ & yes & All (100\%) & \multicolumn{2}{|l|}{ All (100\%) } \\
\hline & $\begin{array}{l}\mathrm{H}_{\text {single }} \\
18\end{array}$ & yes & $\begin{array}{l}\text { moderate to } \\
\text { high }\end{array}$ & high & $2 / 2$ \\
\hline $\begin{array}{l}\text { P09. Was a written plan developed for the period after rehab, } \\
\text { including what you were expected to work on yourself? }\end{array}$ & $\begin{array}{l}\mathrm{H}_{\text {single }} \\
19\end{array}$ & Yes & $\begin{array}{l}\text { small to } \\
\text { moderate }\end{array}$ & moderate & $1 / 1$ \\
\hline $\begin{array}{l}\text { P10. (if "yes" to q. 7): Did you participate in developing the plan (in q. } \\
\text { 7)? }\end{array}$ & $\begin{array}{l}H_{\text {single }} \\
20\end{array}$ & Yes & $\begin{array}{l}\text { small to } \\
\text { moderate }\end{array}$ & small & $1 / 1$ \\
\hline $\begin{array}{l}\text { P11. As part of this plan, were you consulted about whether you } \\
\text { needed follow-up from external personnel after the rehab period? }\end{array}$ & $\begin{array}{l}\mathrm{H}_{\text {single }} \\
21\end{array}$ & Yes & $\begin{array}{l}\text { small to } \\
\text { moderate }\end{array}$ & moderate & $1 / 1$ \\
\hline \multirow[t]{2}{*}{$\begin{array}{l}\text { C06. } P \text { is asked before meetings if he/she wants his/her next of kin } \\
\text { to attend any of the meetings. }\end{array}$} & $\begin{array}{l}\mathrm{H}_{\text {single }} \\
22\end{array}$ & yes & All (100\%) & All (100\%) & \\
\hline & $\begin{array}{l}\mathrm{H}_{\text {single }} \\
23\end{array}$ & yes & zero to small & zero & $2 / 2$ \\
\hline $\begin{array}{l}\text { P07. Were you asked if you wanted your next of kin to attend any of } \\
\text { the meetings? }\end{array}$ & $\begin{array}{l}\mathrm{H}_{\text {single }} \\
24\end{array}$ & Yes & zero to small & small & $1 / 1$ \\
\hline \multirow{2}{*}{$\begin{array}{l}\text { C07. } \mathrm{P} \text { is asked before meetings if he/she wants some of the } \\
\text { professionals }{ }^{\mathrm{b}} \text { he/she will relate to after the rehab to attend any of } \\
\text { the meetings. }\end{array}$} & $\begin{array}{l}\mathrm{H}_{\text {single }} \\
25\end{array}$ & n.a. & All (100\%) & n.a. & n.a. \\
\hline & $\begin{array}{l}\mathrm{H}_{\text {single }} \\
26\end{array}$ & yes & zero to small & small & $1 / 1$ \\
\hline $\begin{array}{l}\text { P08. Were you asked if you wanted external personnel }{ }^{b} \text { to attend } \\
\text { any of the meetings? }\end{array}$ & $\begin{array}{l}\mathrm{H}_{\text {single }} \\
27\end{array}$ & Yes & zero to small & small & $1 / 1$ \\
\hline $\begin{array}{l}\text { Structural QIs (center-reported, marked C) } \\
\text { Process Qls (patient-reported, marked P) }\end{array}$ & $\begin{array}{l}\text { Hypo- } \\
\text { theses }\end{array}$ & $\begin{array}{l}\text { Confirmed } \\
\text { direction }{ }^{1} \text { of } \\
\text { change }\end{array}$ & $\begin{array}{l}\text { Expected } \\
\text { magnitude of } \\
\text { change }\end{array}$ & $\begin{array}{l}\text { Observed } \\
\text { magnitude of } \\
\text { change }\end{array}$ & $\begin{array}{l}\text { Confirmed } \\
\text { hypothesis }\end{array}$ \\
\hline \multicolumn{6}{|l|}{ Assessment, outcomes, and time-points of evaluation } \\
\hline $\begin{array}{l}\text { P01. Were your health condition and life situation assessed during } \\
\text { the first days of your rehab period? }\end{array}$ & $\begin{array}{l}\mathrm{H}_{\text {single }} \\
28\end{array}$ & Yes & zero to small & small & $1 / 1$ \\
\hline $\begin{array}{l}\text { P02. (if "yes" to q. 1): Did the assessments (in q. 1) include both a } \\
\text { physical examination, and q.about mental, and social conditions, } \\
\text { network, home situation and - if relevant - your work situation? }\end{array}$ & $\begin{array}{l}\mathrm{H}_{\text {single }} \\
29\end{array}$ & Yes & zero to small & small & $1 / 1$ \\
\hline \multirow[t]{3}{*}{$\begin{array}{l}\text { C08. The rehab unit uses reliable }{ }^{c} \text { questionnaires and/or functional } \\
\text { tests to assess physical, mental, and/or social conditions. }\end{array}$} & $\begin{array}{l}\mathrm{H}_{\text {single }} \\
30\end{array}$ & yes & All (100\%) & All (100\%) & $1 / 1$ \\
\hline & $\begin{array}{l}\mathrm{H}_{\text {single }} \\
34\end{array}$ & n.a. & All (100\%) & n.a. & n.a. \\
\hline & $\begin{array}{l}\mathrm{H}_{\text {single }} \\
38\end{array}$ & n.a. & $\begin{array}{l}\text { small to } \\
\text { moderate }\end{array}$ & n.a. & n.a. \\
\hline \multicolumn{6}{|l|}{ P's goal/goal attainment is to be assessed ... } \\
\hline \multirow[t]{3}{*}{ C11.... with a reliable instrument } & $\begin{array}{l}\mathrm{H}_{\text {single }} \\
31\end{array}$ & yes & All (100\%) & All (100\%) & \\
\hline & $\begin{array}{l}\mathrm{H}_{\text {single }} \\
35\end{array}$ & yes & All (100\%) & All (100\%) & \\
\hline & $\begin{array}{l}\mathrm{H}_{\text {single }} \\
39\end{array}$ & yes & $\begin{array}{l}\text { moderate to } \\
\text { high }\end{array}$ & high & $3 / 3$ \\
\hline \multirow[t]{3}{*}{ C12.... at the beginning and the end of the rehab period } & $\begin{array}{l}\mathrm{H}_{\text {single }} \\
42\end{array}$ & yes & All (100\%) & All (100\%) & \\
\hline & $\begin{array}{l}\mathrm{H}_{\text {single }} \\
45\end{array}$ & yes & All (100\%) & All (100\%) & \\
\hline & $\begin{array}{l}\mathrm{H}_{\text {single }} \\
48\end{array}$ & yes & $\begin{array}{l}\text { moderate to } \\
\text { high }\end{array}$ & small & $2 / 3$ \\
\hline \multirow[t]{3}{*}{ C13... 3-6 months after the rehab period } & $\begin{array}{l}\mathrm{H}_{\text {single }} \\
51\end{array}$ & yes & All (100\%) & All (100\%) & \\
\hline & $\begin{array}{l}\mathrm{H}_{\text {single }} \\
54\end{array}$ & yes & All (100\%) & All (100\%) & \\
\hline & $\mathrm{H}_{\text {single }}$ & yes & moderate to & high & $3 / 3$ \\
\hline
\end{tabular}


Table 3 Expected and observed change scores for quality indicators (Continued)

\begin{tabular}{|c|c|c|c|c|c|}
\hline & 57 & & high & & \\
\hline \multicolumn{6}{|l|}{$\mathrm{P}^{\prime} \mathrm{s}$ function is to be registered ... } \\
\hline \multirow[t]{3}{*}{ C14. ... using a reliable instrument } & $\begin{array}{l}\mathrm{H}_{\text {single }} \\
32\end{array}$ & yes & All (100\%) & All (100\%) & $1 / 1$ \\
\hline & $\begin{array}{l}\mathrm{H}_{\text {single }} \\
36\end{array}$ & n.a. & All (100\%) & n.a. & n.a. \\
\hline & $\begin{array}{l}\mathrm{H}_{\text {single }} \\
40\end{array}$ & n.a. & small & n.a. & n.a. \\
\hline \multirow[t]{4}{*}{ C15.... at the beginning and the end of the rehab period } & $\begin{array}{l}\mathrm{H}_{\text {single }} \\
43\end{array}$ & yes & All (100\%) & All (100\%) & $1 / 1$ \\
\hline & & n.a. & & & \\
\hline & $\begin{array}{l}\mathrm{H}_{\text {single }} \\
46\end{array}$ & n.a. & All (100\%) & n.a. & n.a. \\
\hline & $\begin{array}{l}\mathrm{H}_{\text {single }} \\
49\end{array}$ & & small & n.a. & n.a. \\
\hline \multirow[t]{3}{*}{ C16.... 3-6 months after the rehab period } & $\begin{array}{l}\mathrm{H}_{\text {single }} \\
52\end{array}$ & n.a. & All (100\%) & n.a. & n.a. \\
\hline & $\begin{array}{l}\mathrm{H}_{\text {single }} \\
55\end{array}$ & yes & All (100\%) & All (100\%) & \\
\hline & $\begin{array}{l}\mathrm{H}_{\text {single }} \\
58\end{array}$ & yes & moderate to & high & $2 / 2$ \\
\hline \multicolumn{6}{|l|}{$P^{\prime} s$ health-related quality of life is to be assessed ... } \\
\hline \multirow[t]{3}{*}{ C17. ... using a reliable instrument } & $\begin{array}{l}\mathrm{H}_{\text {single }} \\
33\end{array}$ & yes & All (100\%) & All (100\%) & \\
\hline & $\begin{array}{l}\mathrm{H}_{\text {single }} \\
37\end{array}$ & yes & All (100\%) & All (100\%) & $3 / 3$ \\
\hline & $\begin{array}{l}\mathrm{H}_{\text {single }} \\
41\end{array}$ & yes & $\begin{array}{l}\text { moderate to } \\
\text { high }\end{array}$ & high & \\
\hline \multirow[t]{3}{*}{ C18.... at the beginning and the end of the rehab period } & $\begin{array}{l}\mathrm{H}_{\text {single }} \\
44\end{array}$ & yes & All (100\%) & All (100\%) & \\
\hline & $\begin{array}{l}\mathrm{H}_{\text {single }} \\
47\end{array}$ & yes & All (100\%) & All (100\%) & \\
\hline & $\begin{array}{l}\mathrm{H}_{\text {single }} \\
50\end{array}$ & yes & $\begin{array}{l}\text { moderate to } \\
\text { high }\end{array}$ & high & $3 / 3$ \\
\hline \multirow[t]{3}{*}{ C19. ... 3-6 months after the rehabperiod } & $\begin{array}{l}\mathrm{H}_{\text {single }} \\
53\end{array}$ & n.a. & All (100\%) & n.a. & n.a. \\
\hline & $\begin{array}{l}\mathrm{H}_{\text {single }} \\
56\end{array}$ & yes & All (100\%) & All (100\%) & \\
\hline & $\begin{array}{l}\mathrm{H}_{\text {single }} \\
59\end{array}$ & yes & $\begin{array}{l}\text { moderate to } \\
\text { high }\end{array}$ & high & $2 / 2$ \\
\hline \multicolumn{6}{|l|}{ As a result of the rehab } \\
\hline $\begin{array}{l}\text { P12.... have you achieved one or several goals that are important to } \\
\text { you? }\end{array}$ & $\begin{array}{l}\mathrm{H}_{\text {single }} \\
60\end{array}$ & No & zero to small & small & $0 / 1$ \\
\hline $\begin{array}{l}\text { P13... have you achieved an improvement in your physical, mental, } \\
\text { and/or social functioning that is important to you? }\end{array}$ & $\begin{array}{l}H_{\text {single }} \\
61\end{array}$ & Yes & zero to small & small & $1 / 1$ \\
\hline P14.... do you think your quality of life has improved? & $\begin{array}{l}\mathrm{H}_{\text {single }} \\
62\end{array}$ & No & zero to small & small & $0 / 1$ \\
\hline IN TOTAL (changes in single item scores) & & & & & $\begin{array}{l}44 / 53 \\
\text { confirmed }\end{array}$ \\
\hline
\end{tabular}

1 expected direction is positive or stable for all the hypotheses, Q/ quality indicator, Htotalxx hypotheses concerning change in total pass rates, followed by hypothesis number, Hsinglexx hypotheses concerning change in single indicator pass rates, followed by hypothesis number, rehab rehabilitation, $q$ question; ${ }^{a}$ the team $=$ the interdisciplinary team or a professional representing the team; ${ }^{b}$ external personnel, such as a physiotherapist, general practitioner, or - if relevant - the labor and welfare administration or a person from work; ${ }^{c}$ quality-assured/validated questionnaires or tests, n.a. Not applicable 
Median pass rate (PR, total) reported from providers Structure quality indicators

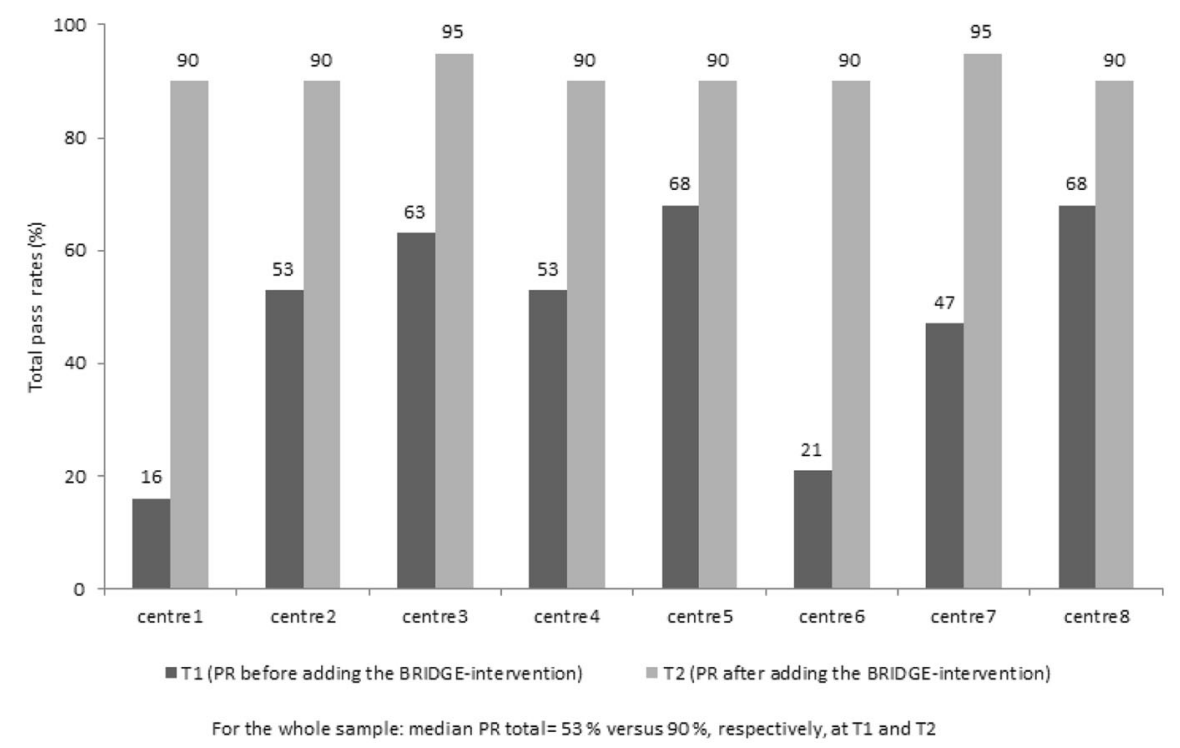

Median pass rate ( $P R$, total) reported from patients Process and outcome indicators

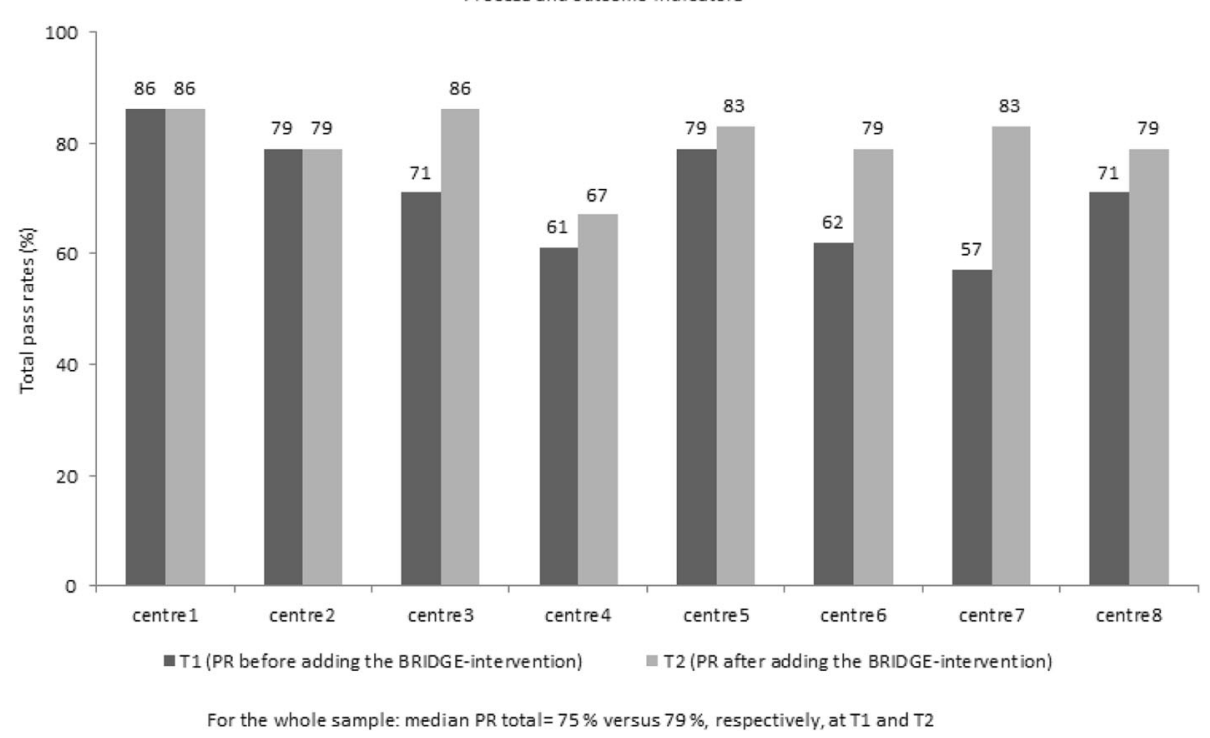

Fig. 2 Longitudinal changes in total pass rates in the time interval from T1 to T2

From both the service and the user perspectives, the largest improvements from $\mathrm{T} 1$ to $\mathrm{T} 2$ were related to externals involved in planning the follow-up (Fig. 3). The change scores were $62.5 \%$ for the structure indicator $(\mathrm{C} 10)$ and $20 \%$ for the matching process indicator (P11) (Additional file 3). The magnitude of these improvements confirmed the predefined expectation (Table 3, Additional file 3).

\section{Discussion}

In this study, we evaluated the responsiveness of a newly developed QI set for rehabilitation services for people with RMDs. A construct approach was used, with predefined hypotheses regarding expected changes in QI pass rates after the addition of a new rehabilitation intervention to the traditional programs delivered at eight rehabilitation centers in specialist care. The results show 
Single indicator pass rates (\%) reported from providers

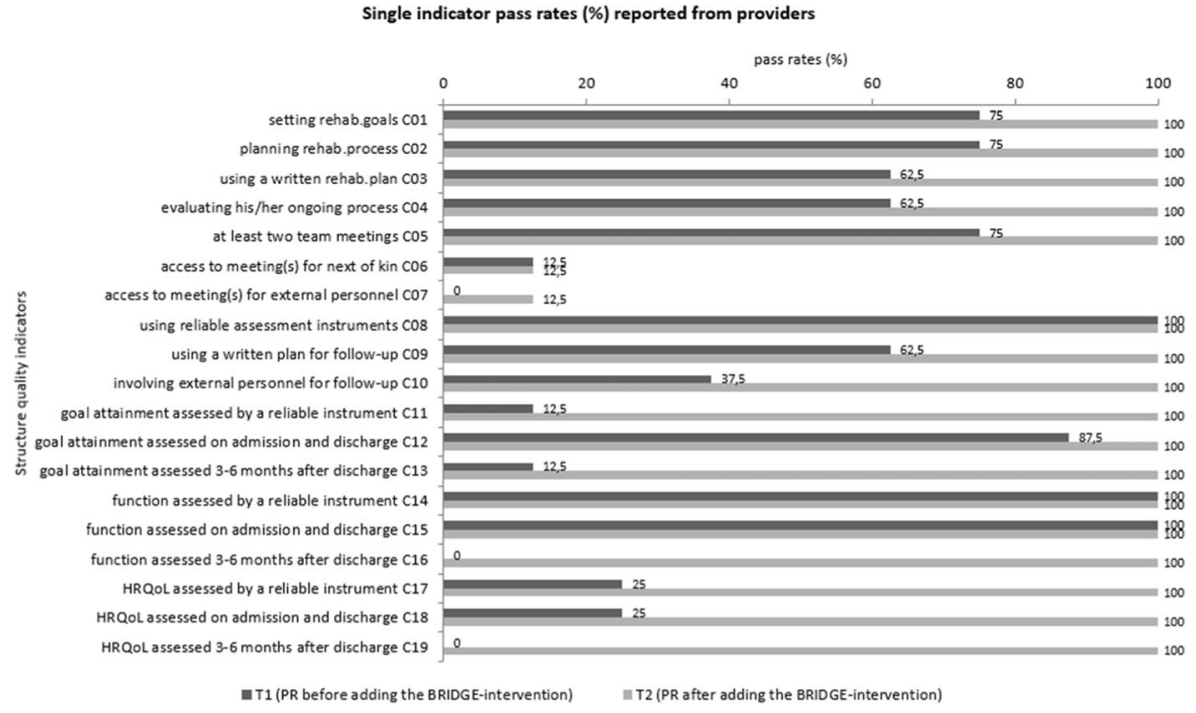

Single indicator pass rates $(\%)$ reported from patients

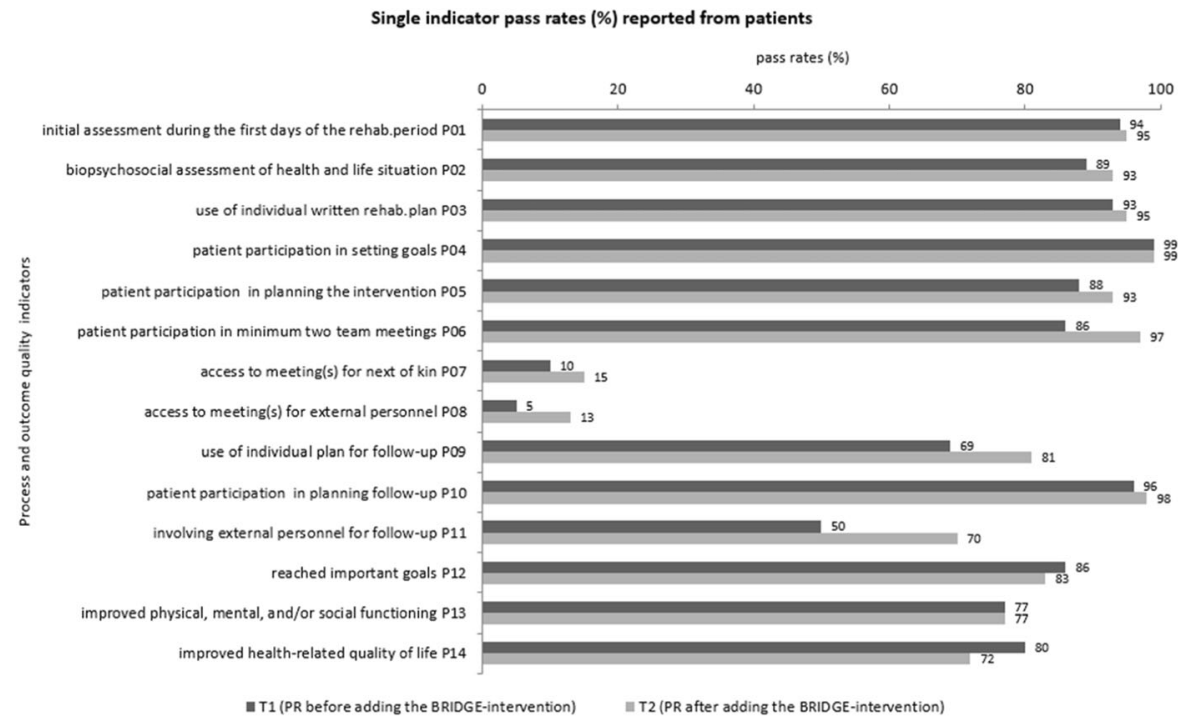

Fig. 3 Longitudinal changes in single indicator pass rates in the time interval from T1 to T2

adequate responsiveness, with more than $75 \%$ of the predefined hypotheses being confirmed.

Although most of the hypotheses were confirmed, some reasons for unconfirmed hypotheses are worth noting. First, the change scores were larger than expected for three of the structure indicators. When developing the hypotheses, we assumed that implementation of written procedures, which is required for a shift from "no" to "yes" on structure indicators, would be difficult to achieve for the centers. However, more respondents answered "yes" at T2 than expected. One reason may be that providers regarded the BRIDGE booklets for patients and providers as written procedures. Whether the centers continued to use these booklets after the research period would be interesting to explore in a follow-up study.
Second, the change scores were smaller than expected for three of the process indicators, likely because quality was already in line with normative standards at $\mathrm{T} 1$. Indeed, we found surprisingly high PR values for the three indicators at $\mathrm{T} 1$ (93, 88, and $86 \%$, respectively), and the potential for change in these indicators was therefore negligible. For other indicators, we had several hypotheses $(n=16)$ regarding maintenance of good quality from $\mathrm{T} 1$ to $\mathrm{T} 2$, which were confirmed. Consequently, our data suggest that the QI set will capture efforts to improve or prove good quality over time, implying the double intention when monitoring quality: In addition to measuring quality improvements, it is important to know whether established good quality is maintained. 
Third, we expected stable or improved outcome indicators both after the traditional rehabilitation program (T1) and after the BRIDGE intervention (T2). In line with these expectations, we found that PR values at $\mathrm{T} 1$ and T2 were equal for P13 (improved physical mental, and/or social functioning), whereas the change scores for P12 (reached important goals) and P14 (improved HRQoL) were slightly negative $(-3 \%$ and $-8 \%$, respectively). Also, when considering the outcome indicators for one of the subgroups, the observed change score for total PR differed from what we hypothesized. Many factors may have influenced these results, such as variation in patient groups among centers, and factors not captured by the chosen baseline characteristics, such as motivation, ability to be compliant, and individual decisions about when to focus on different goals and issues through the follow-up period. As others have highlighted $[19,20,34-36]$, structure and processes of provided care explain only a portion of what influences outcomes. Nevertheless, patient-reported clinical outcomes should remain relevant for monitoring quality because of the expected interplay among all dimensions in the concept of quality [15, 34-37]. However, further research is needed regarding the kind of outcomes that are most sensitive to detecting differences in quality of care and the evidence for potential links among structure, process, and outcome indicators [15, 20,35-37].

\section{Strengths and limitations}

The strengths of this study include a methodology guided by the COSMIN checklist [32], a large patient sample size, and high data quality with a response rate of $100 \%$ for center-reported QIs and more than $80 \%$ for patient-reported QIs. However, the use of questionnaires in Norwegian may have induced a sample bias of having few participants from ethnic minority groups. Apart from this, we believe that the study group was representative and that the results may apply to the broad RMD population receiving specialized rehabilitation in Norway [38]. The most important limitation in our study is the modest number of rehabilitation units. However, this manageable sample enabled us to offer tailored guidance to prepare for high fidelity when adding the new BRIDGE program at each center. Moreover, the number of Norwegian institutions in specialized care delivering rehabilitation services for people with RMDs is limited, and our sample include both rehabilitation institutions and hospital rehabilitation departments across rural and urban regions. Still, the indicator set might function differently within rehabilitation services and funding systems abroad. Therefore, responsiveness should be further tested in studies in different countries and levels of care.
Finally, in our evaluation of responsiveness, all hypotheses counted equally. This choice can be questioned because we did not form the same number of hypotheses for each indicator. The greater number of hypotheses for the structure indicators may have led to an unbalanced evaluation of the interplaying triad of structure, process, and outcome indicators. However, we note that we assessed responsiveness for the QI set in its entirety and not for separate subscales. Although center- and patient-reported QIs are separate questionnaires, we recommend that they be used simultaneously to cover the concept of quality from both the service and patient perspectives.

\section{Implications}

Quality of care is receiving increasing emphasis and interest in research, clinical practice, and public documents [12-15]. For different stakeholders, such as patients, health professionals, researchers, and policy makers, it is important to have tools for delivering and demanding optimal rehabilitation [39]. This QI set offers a timely opportunity to establish quality-of-rehabilitation benchmarks, promote important steps toward highquality rehabilitation, and track trends over time. As far as we know, this QI set is the first indicator set developed for use in rehabilitation for people with RMDs, covering structure, process, and outcome quality [21]. In the pilot study, the QI set was proven feasible, with satisfactory face and content validity [21]. Our results support that the QI set also can be used in longitudinal evaluations of quality in or between rehabilitation services. Such information may be useful for providers in evaluating local quality improvement initiatives or continuing efforts to keep the service in line with the recommendations. Additionally, the information may be useful for policy makers, funders, and researchers in following trends over time and trajectories across care levels and identifying potential problems or issues to consider when planning for future management of rehabilitation. A further important application is the facilitation of patients' choice of providers, by producing information about the quality of rehabilitation available.

\section{Conclusion}

We found that this QI set for rehabilitation was responsive when applied in rehabilitation services for adults with various RMD conditions. The QI set holds potential as an important tool for capturing changes or monitoring maintenance in the multidimensional arena of quality in rehabilitation. Our results support the use of this QI set in clinical practice and research when the intention is to evaluate quality over time from both the system and user perspectives. This QI set may be useful for quality improvement and benchmarking in and between rehabilitation services. 


\section{Supplementary Information}

The online version contains supplementary material available at https://doi. org/10.1186/s12913-021-06164-2.

Additional file 1. Organization of rehabilitation programs at participating centers.

Additional file 2. Baseline characteristics of patients in the BRIDGE trial when the $\mathrm{Q}$ set was distributed.

Additional file $\mathbf{3}$. Predefined hypotheses with rationale and results.

\section{Abbreviations}

Ql: Quality indicator; RMD: Rheumatic and musculoskeletal disease; STARETIC: Scandinavian team-arthritis register - european team initiative for care research; PR: Pass rate; PSFS: Patient-specific functional scale; 30secSTS: The 30-s sit-to-stand test; EQ-5D: EuroQoL 5D-5L-health related quality of life; COSMIN: Consensus-based standards for the selection of health measurement instruments; ICC: Intraclass correlation coefficient; PT: Physiotherapist; OT: Occupational therapist

\section{Acknowledgements}

The authors would like to thank all of the patients, health professionals, and leaders at the participating centers for their valuable contribution to this project.

\section{Authors' contributions}

All authors were involved in drafting the article or revising it critically for important intellectual content. All authors approved the final version to be submitted for publication. Study conception or design: ALSS, GB, IK, HD, MA, IB, TD, SGE, GOF, ASH, ÅK, ADL, KT, HLV, and AMA. Acquisition of data: IB, SGE, GOF, ASH, ÅK, ADL, KT, HLV, and AMA. Analysis and interpretation of data: ALSS, GB, HD, and IK. ALSS had full access to all of the data in the study and takes responsibility for the integrity of the data and the accuracy of the data analysis.

\section{Funding}

This work was supported by the Research Council of Norway. Grant number: 260661. The funder had no role in design of the project, in collection analysis, or interpretation of data, or in writing the manuscript.

\section{Availability of data and materials}

The datasets used and analysed during the current study are available from the corresponding author on reasonable request.

\section{Ethics approval and consent to participate}

The study was approved by the Norwegian Regional Committee for Medical Research Ethics (REK South-East, 2017/665). All participants provided a written informed consent. Our study was performed in accordance with the Declaration of Helsinki.

\section{Consent for publication}

Not applicable.

\section{Competing interests}

The authors declare that they have no competing interests.

\footnotetext{
Author details

${ }^{1}$ National Advisory Unit on Rehabilitation in Rheumatology, Diakonhjemmet Hospital, PO Box 23, Vinderen, N-0319 Oslo, Norway. ${ }^{2}$ Diakonhjemmet Hospital, PO Box 23, Vinderen, N-0319 Oslo, Norway. ${ }^{3}$ Hospital for Rheumatic Diseases Lillehammer, Margrethe Grundtvigs veg 6, N-2609 Lillehammer, Norway. ${ }^{4}$ Sørlandet Hospital Arendal, PO Box 416, Lundsiden, N-4604 Kristiansand, Norway. ${ }^{5}$ Vikersund Rehabilitation Center, Haaviks vei 25, N-3370 Vikersund, Norway. ${ }^{6}$ Hospital for Rheumatic Diseases Haugesund, PO Box 2175, N-5504 Haugesund, Norway. ${ }^{7}$ Rehabilitering Vest Rehabilitation Center, PO Box 2175, N-5504 Haugesund, Norway. ${ }^{8}$ Muritunet Rehabilitation Center,

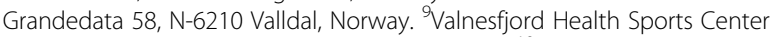
Østerkløftveien 249, N-8215 Valnesfjord, Norway. ${ }^{10}$ Meråker Rehabilitation Center, Østigardsveien 24, N-7530 Meråker, Norway.
}

Received: 18 November 2020 Accepted: 13 January 2021 Published online: 20 February 2021

\section{References}

1. Krishnan E, Lingala B, Bruce B, Fries JF. Disability in rheumatoid arthritis in the era of biological treatments. Ann Rheum Dis. 2012;71(2):213-8.

2. Kolasinski SL, Neogi T, Hochberg MC, Oatis C, Guyatt G, Block J, et al. 2019 American College of Rheumatology/Arthritis Foundation guideline for the Management of Osteoarthritis of the hand, hip, and knee. Arthritis Rheum. 2020;72(2):220-33

3. Macfarlane GJ, Kronisch C, Dean LE, Atzeni F, Häuser W, Fluß E, et al. EULAR revised recommendations for the management of fibromyalgia. Ann Rheum Dis. 2017:76(2):318-28.

4. Frontera WR, Silver JK, Rizzo TD, Custodio CM, Ibanez K, Stein J, et al. Essentials of physical medicine and rehabilitation : musculoskeletal disorders, pain, and rehabilitation. Philadelphia: Elsevier; 2019.

5. Meesters J, Hagel S, Klokkerud M, Stovgaard I, Bremander A, Grotle M, et al. Goal-setting in multidisciplinary team care for patients with rheumatoid arthritis: an international multi-center evaluation of the contents using the international classification of functioning, disability and health as a reference. J Rehabil Med. 2013;45(9):888-99.

6. Garrido-Cumbrera M, Hillmann O, Mahapatra R, Trigos D, Zajc P, Weiss L, et al. Improving the Management of Psoriatic Arthritis and Axial Spondyloarthritis: roundtable discussions with healthcare professionals and patients. Rheumatol Ther. 2017;4(2):219-31.

7. Berdal G, Sand-Svartrud A-L, Bø I, Dager TN, Dingsør A, Eppeland SG, et al. Aiming for a healthier life: a qualitative content analysis of rehabilitation goals in patients with rheumatic diseases. Disabil Rehabil. 2018;40(7):765-78.

8. Malm K, Bremander A, Arvidsson B, Andersson MLE, Bergman S, Larsson I. Predictors of severe self-reported disability in RA in a long-term follow-up study. Disabil Rehabil. 2015;37(8):686-91.

9. Malm K, Bergman S, Andersson M, Bremander A. The influence of lifestyle habits on quality of life in patients with established rheumatoid arthritis-a constant balancing between ideality and reality. Int J Qual Stud Health Wellbeing. 2016;11(1):30534-9.

10. Kamper SJ, Apeldoorn AT, Chiarotto A, Smeets RJEM, Ostelo RWJG, Guzman $J$, et al. Multidisciplinary biopsychosocial rehabilitation for chronic low back pain: Cochrane systematic review and meta-analysis. BMJ. 2015;350:h444.

11. World Health Organization. World report on disability; 2011.

12. Wade D. Rehabilitation - a new approach. Overview and part one: the problems. Clin Rehabil. 2015;29(11):1041-50.

13. The Norwegian Directorate of Health. Norwegian board of health Supervison. Oslo: Helsedirektoratet; 2015.

14. The Office of the Auditor General Document 3:11 (2011-2012). The Office of the Auditor General's investigation into rehabilitation in the health service. Norway; 2012.

15. Mahmood SB, Lesuis NMD, van Tuyl LHDP, van Riel PMDP, Landewé RMDP. Quality in rheumatoid arthritis care. Best Pract Res Clin Rheumatol. 2015; 29(4-5):664-79.

16. Lawrence M, Olesen F. Indicators of quality in health care. Eur J Gen Pract. 1997:3(3):103-8

17. Donabedian A. The quality of care. How can it be assessed? JAMA. 1988; 260(12):1743-8

18. Donabedian A. Evaluating the quality of medical care. Milbank Q. 2005:83(4): 691-729.

19. Eldar R. Methodology matters - XIII. Quality of care in rehabilitation medicine. Int J Qual Health Care. 1999;11(1):73-9.

20. Mainz J. Defining and classifying clinical indicators for quality improvement. Int J Qual Health Care. 2003;15(6):523-30.

21. Johansen I, Klokkerud M, Anke A, Børke J-B, Glott T, Hauglie U, et al. A quality indicator set for use in rehabilitation team care of people with rheumatic and musculoskeletal diseases; development and pilot testing BMC Health Serv Res. 2019;19(1):265-76.

22. National Library of Medicine: The BRIDGE Rehabilitation Trial (BRIDGE) 2017 [updated 02032020]. Available from: https://clinicaltrials.gov/ct2/show/ NCT03102814. Acced 8 May 2019

23. Stratford P, Gill C, Westaway M, Binkley J. Assessing disability and change on individual patients: a report of a patient specific measure. Physiother Can. 1995:47(4):258-63.

24. Moseng T, Tveter A, Holm I, Dagfinrud H. Pasient-Spesifikk Funksjons Skala: et nyttig verktøy for fysioterapeuter i primærhelsetjenesten. Fysioterapeuten. 2013;80:2. 
25. Klokkerud M, Hagen KB, Kjeken I, Bremander A, Horslev-Petersen K, Vlieland TV, et al. Development of a framework identifying domains and elements of importance for arthritis rehabilitation. J Rehabil Med. 2012;44(5):406-13.

26. Grotle M, Klokkerud M, Kjeken I, Bremander A, Hagel S, Strömbeck B, et al. What's in the black box of arthritis rehabilitation? A comparison of rehabilitation practice for patients with inflammatory arthritis in northern Europe. J Rehabil Med. 2013;45(5):458-66.

27. Csuka M, McCarty DJ. Simple method for measurement of lower extremity muscle strength. Am J Med. 1985;78(1):77-81.

28. Jones CJ, Rikli RE, Beam WC. A 30-s chair-stand test as a measure of lower body strength in community-residing older adults. Res Q Exerc Sport. 1999; 70(2):113-9.

29. Klokkerud M, Dagfinrud H, Uhlig T, Dager TN, Furunes KA, Klokkeide Å, et al. Developing and testing a consensus-based core set of outcome measures for rehabilitation in musculoskeletal diseases. Scand J Rheumatol. 2018;47(3): 225-34

30. EuroQol Office: EQ-5D-5L 2017 [updated 18042017]. Available from: https:// euroqol.org/eq-5d-instruments/eq-5d-5l-about/. Accessed 8 june 2020.

31. Mokkink LB, Terwee CB, Patrick DL, Alonso J, Stratford PW, Knol DL, et al. The COSMIN study reached international consensus on taxonomy, terminology, and definitions of measurement properties for health-related patient-reported outcomes. J Clin Epidemiol. 2010;63(7):737-45.

32. COSMIN. COSMIN study design checklist for patient-reported outcome measurement instruments 2019; 2019. Available from: https://www.cosmin nI/wp-content/uploads/COSMIN-study-designing-checklist_final.pdf. Accessed 10 February 2020

33. de Vet HCW, Terwee CB, Mokkink LB, Knol DL. Measurement in medicine : a practical guide. Cambridge: Cambridge University Press; 2011.

34. Ramalho A, Castro P, Gonçalves-Pinho M, Teixeira J, Santos JV, Viana J, et al. Primary health care quality indicators: an umbrella review. PLoS One. 2019; $14: 8$.

35. Mant J. Process versus outcome indicators in the assessment of quality in health care. Int J Qual Health Care. 2001;13(6):475-80.

36. Bilimoria KY. Facilitating quality improvement: pushing the pendulum Back toward process measures. JAMA. 2015;314(13):1333-4.

37. Stelfox HT, Straus SE. Measuring quality of care: considering measurement frameworks and needs assessment to guide quality indicator development. J Clin Epidemiol. 2013;66(12):1320-7.

38. Berdal G, Bø I, Dager TN, Dingsør A, Eppeland SG, Hagfors J, et al. Structured goal planning and supportive telephone follow-up in rheumatology care: results from a pragmatic, stepped-wedge, cluster-randomized trial. Arthritis Care Res. 2018;70(11):1576-86.

39. Gratacós J, Luelmo J, Rodríguez J, Notario J, Marco TN, de la Cueva P, et al. Standards of care and quality indicators for multidisciplinary care models for psoriatic arthritis in Spain. Rheumatol Int. 2018;38(6):1115-24.

\section{Publisher's Note}

Springer Nature remains neutral with regard to jurisdictional claims in published maps and institutional affiliations.

Ready to submit your research? Choose BMC and benefit from:

- fast, convenient online submission

- thorough peer review by experienced researchers in your field

- rapid publication on acceptance

- support for research data, including large and complex data types

- gold Open Access which fosters wider collaboration and increased citations

- maximum visibility for your research: over $100 \mathrm{M}$ website views per year

At $\mathrm{BMC}$, research is always in progress.

Learn more biomedcentral.com/submissions 